\title{
Critical current density and magnetization studies on $\mathrm{Bi}(\mathrm{Pb}) \mathrm{SrCaCuO}$
}

\author{
P K MISHRA, SHAILENDRA KUMAR, G RAVIKUMAR, P \\ CHADDAH, B A DASANNACHARYA, RAM PRASAD* and \\ N C SONI* \\ Nuclear Physics Division, *Metallurgy Division, Bhabha Atomic Research Centre, Bombay \\ 400085 , India.
}

\begin{abstract}
High $T_{c}$ phase $\left(T_{c} \sim 110 \mathrm{~K}\right)$ has been obtained in $\mathrm{Bi}-\mathrm{Sr}-\mathrm{Ca}-\mathrm{Cu}-\mathrm{O}$ system by partially substituting $\mathrm{Bi}$ by $\mathrm{Pb}$. Magnetic hysteresis has been measured as a function of temperature. Critical current densities have been measured at $77 \mathrm{~K}$ both by transport and a.c. magnetization method in bulk samples for various concentrations of $\mathrm{Pb}$. The results show that substitution of $15 \mathrm{at} \% \mathrm{~Pb}$ for $\mathrm{Bi}$ is most preferable for higher critical current density.
\end{abstract}

Keywords. Critical current; superconductivity; magnetization measurements.

\section{Introduction}

Following the discovery of superconductivity in $\mathrm{Bi}-\mathrm{Sr}-\mathrm{Ca}-\mathrm{Cu}-\mathrm{O}$ system (Michel et al 1987; Maeda et al 1988), it is well established that the compound exhibits superconductivity in two phases, viz. a high $T_{c} 2223$ phase $\left(T_{c} \sim 110 \mathrm{~K}\right)$ and a low $T_{c} 2212$ phase $\left(T_{c} \sim 80 \mathrm{~K}\right)$. The two phases are normally found to coexist, so that the zero resistance is attained only below $85 \mathrm{~K}$.

Efforts have been made to stabilize the high $T_{c}(110 \mathrm{~K})$ phase by different methods. Limited success has been obtained (Shi et al 1988) in pure compounds to achieve $\rho=0$ at $110 \mathrm{~K}$. The procedure involves long sintering times and is complicated. An alternative approach (Statt et al 1988) is to dope $\mathrm{Pb}$ for bismuth which aids the growth of $110 \mathrm{~K}$ phase. The latter procedure is more common for its simplicity, but is believed to result in multi-phase samples. In this paper we present our studies on critical current densities and low field magnetization hysteresis in $\mathrm{Bi}_{2-x} \mathrm{~Pb}_{x} \mathrm{Sr}_{2} \mathrm{Ca}_{2} \mathrm{Cu}_{3} \mathrm{O}_{y}$ samples for $0 \cdot 2 \leqslant x \leqslant 0.4$.

\section{Experimental details and results}

Samples were prepared by reaction (Tomy et al 1989) of $\mathrm{Bi}_{2} \mathrm{O}_{3}, \mathrm{PbO}$ and $\mathrm{Sr}_{2} \mathrm{Ca}_{2} \mathrm{Cu}_{3} \mathrm{O}_{7}$ with two different types of heat treatments. In the first type (referred to as group I), the mixture was calcined in air at $820^{\circ} \mathrm{C}$ for $2 \mathrm{~h}$, then pelletized and sintered at $855^{\circ} \mathrm{C}$ for $96 \mathrm{~h}$ in air and then slow-cooled. For the other group (referred to as group II), the mixture was first pressed and flashed to $900^{\circ} \mathrm{C}$ for $5 \mathrm{~min}$ for surface-melting followed by sintering at $855^{\circ} \mathrm{C}$ for $96 \mathrm{~h}$ in air and then slow-cooled.

Transport measurements of $J_{c}$ were made (Malik et al 1988) at $77 \mathrm{~K}$ from the $\mathrm{V}-\mathrm{I}$ curve. The results are shown in table 1 . We note that $J_{c}$ value is lower than that 
obtained in $\mathrm{YBaCuO}$ system. A peak in $J_{c}$ is obtained for $x=0.3$ for both groups of samples without any significant change in $T_{c}$.

The hysteresis curves are measured using an $\mathrm{AC}(317 \mathrm{~Hz})$ susceptibility instrument (Radhakrishnamurthy et al 1978) coupled with a flow-type liquid nitrogen cryostat. The sample and a copper constantan thermocouple are encapsulated in a nylon sample holder which is filled with Apiezone $\mathbf{N}$ grease..The sample holder rests in a glass tube and its position is adjustable with respect to the secondary coils of the susceptibility instrument. Temperature is varied in the range of $T=77 \mathrm{~K}$ to $120 \mathrm{~K}$ with $\Delta T=$ $\pm 0.5 \mathrm{~K}$ by controlling the rate of flow of the nitrogen gas through liquid nitrogen. Samples in the pellet geometry are used in this study. The maximum cycling field, $H_{\max }$, can be varied between 1 Gauss and 10 Gauss. $T_{c}$ was measured as the temperature of diamagnetic onset with a cycling field $H_{\max }=8 \mathrm{Gauss}$. $J_{c}$ can also be estimated from the remnant magnetization $M_{r}$ at $77 \mathrm{~K}$ in the field of 8 Gauss. The remnant magnetization is indicated schematically in figure 1 and gives a measure of the transport $J_{c}$ (Shailendra Kumar et al 1990). The data obtained from the low field hysteresis are shown in table 2.

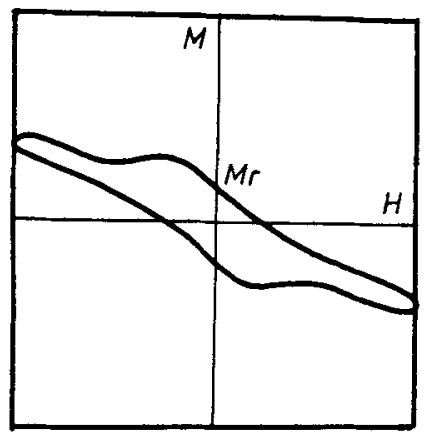

Figure 1. Schematic of hysteresis curve for $H_{\max }=8$ Gauss at $77 \mathrm{~K}$.

Table 1. Transport $J_{c}$ and $T_{\mathrm{c}}$ of various samples.

\begin{tabular}{lcccc}
\hline$x$ & $\begin{array}{c}\text { Gr. I. } J_{c} \\
\left(\mathrm{amp} / \mathrm{cm}^{2}\right)\end{array}$ & $T_{c}(\mathrm{~K})$ & $\begin{array}{c}\text { Gr. II. } J_{c} \\
\left(\mathrm{amp} / \mathrm{cm}^{2}\right)\end{array}$ & $T_{c}(\mathrm{~K})$ \\
\hline 0.2 & 0.70 & 110 & Very small & 108 \\
0.3 & 12.30 & 110 & 6.86 & 110 \\
0.4 & 1.40 & 108 & 3.62 & 110 \\
\hline
\end{tabular}

Table 2. Remnant magnetization $M$, for different concentrations of $\mathrm{Pb}$.

\begin{tabular}{lcc}
\hline$x$ & $\begin{array}{c}\text { Gr. I. 2M } \\
\text { (arbitrary unit) }\end{array}$ & $\begin{array}{c}\text { Gr. II. 2Mr } \\
\text { (arbitrary unit) }\end{array}$ \\
\hline 0.2 & 0.0 & 1.0 \\
0.3 & 11.5 & 4.5 \\
0.4 & 8.5 & 2.0 \\
\hline
\end{tabular}


$M_{r}$ also peaks at $x=0.3$ and this correlates qualitatively with the transport measurement.

\section{Conclusion}

The transport $J_{c}$ measured from the $\mathrm{V}$-I curve shows a clear peak at $x=0.3$ irrespective of the preparation route followed, while $T_{c}$ (as measured from the diamagnetic onset) is unchanged (to within $2 \mathrm{~K}$ ) as $x$ is varied from 0.2 to 0.4 . The stronger intergrain coupling at $x=0.3$ is also reflected in the fact that $M_{r}$ peaks at $x=0.3$.

The addition of lead helps stabilize the 2223 phase and its concentration is not crucial for high $T_{c}$. Our results show that the best intergrain coupling is achieved for $x=0.3$.

\section{References}

Maeda H, Tanaka Y, Fukutomi M and Asano T $1988 J$ pn J. Appl. Phys. Lett. 27 L209

Malik M K, Nair V D, Biswas A R, Raghavan R V, Chaddah P, Mishra P K, Ravi Kumar G and Dasannacharya B A 1988 Appl. Phys. Lett. 521525

Michel C, Hervieu M, Borel M M, Grandin A, Deslandes F, Provost J and Raveau B 1987 Z. Phys. B68 421

Radhakrishnamurthy C, Likhite S D and Sahasrabudhe P W 1978 Proc. Indian Acad. Sci.-Chem. Sci. A78 245

Shailendra Kumar, Ravikumar G, Mishra P K, Chaddah P, Dasannacharya B A, Ram Prasad and Soni N C 1990 Presented at the Int. Conf. on Superconductivity (to be published)

Shi D, Blank M, Patel M, Hinks D G, Mitchell A W, Vandervoot K and Claus H 1988 Physica C156 822

Statt B W, Wang Z, Lee M J G, Yakhmi J V, De Camargo P C. Major J F and Rutter J W 1988 Physica C156 251

Tomy C V, Ram Prasad, Soni N C, Kalyan A and Malik S K 1989 Paper presented at M²S-HTSC, Stanford 